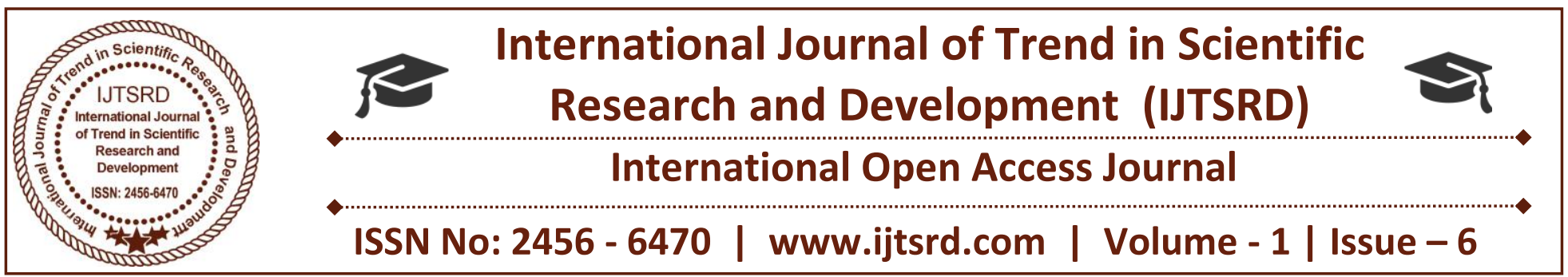

\title{
Bacteriological Profile of Skin Moisturizing Lotions during use and its Potential Hazards
}

\author{
Namrata G. Shukla \\ Department of Microbiology, \\ S.S.E.S.A's Science College, \\ Congress Nagar, Nagpur
}

\author{
Pranita A. Gulhane \\ Department of Microbiology, \\ S.S.E.S.A's Science College, \\ Congress Nagar, Nagpur
}

\author{
Ashok V. Gomashe \\ Department of Microbiology, \\ S.S.E.S.A's Science College, \\ Congress Nagar, Nagpur
}

\section{ABSTRACT}

Skin moisturizing lotions serve as the essential needs of modern lifestyle. Moreover its composition serves as luxurious source for the growth of varied microorganisms as it contain special additives like plant extracts, fatty acids and vitamins. Hence the present investigation was carried out to evaluate and screen the bacterial contaminants from skin moisturizing lotions and to study its antibiotic resistance pattern. A total of 22 different types of skin moisturizing lotions representing different brands were collected. Out of which, 8 samples showed presence of two potential bacterial contaminants including 7 isolates of Staphylococcus aureus and 8 isolates Pseudomonas aeruginosa. The results of the test revealed that all the isolates of $S$. aureus were sensitive against tested antibiotics while 2 isolates of $P$. aeruginosa were resistant to Gentamycin and Carbenicillin and 1 to Levofloxacin. The findings of this study conclude that skin moisturizing lotions may contain bacterial contaminants such Staphylococcus aureus and Pseudomonas aeruginosa in tested products posing a serious threat for the consumers. When the bacterial contaminants were tested against Neem and Daru Haldi extracts, it was found that the extracts were effective against it.

Keywords: Skin moisturizing lotion, Bacterial contaminants, Staphylococcus aureus, Pseudomonas aeruginosa

\section{INTRODUCTION}

Cosmetics are substances or products used to enhance or alter the appearance or fragrance of the body. Cosmetics serve as the essential needs of a modern lifestyle as they are grossly used by millions of people across the world [1]. Many cosmetics are designed for use of applying to the face and hair. Common cosmetics include lipstick, mascara, eye shadow, foundation, skin cleansers and skin lotions, shampoo, hairstyling products (gel, hair spray, etc.) and perfume. They are generally mixtures of chemical compounds. Cosmetics may contain surfactants, proteins, oils, emulsifiers, vitamins, minerals and natural plant extracts mixed together with water. This composition of cosmetics serves as luxurious source for the growth of varied microorganisms [2]. Hence there are many species that are capable to grow in them, and in general it is the water activity of the product that determines if it is susceptible to the growth of microorganisms. However biodegradation of the product takes place which enhances the risk of infection to the consumers [3] [4]

Skin moisturizing lotions contain special additives like plant extracts, fatty acids and vitamins. These additives could serve as nutrients for microorganisms. The cause of bacterial contamination is believed to be negligence while practicing manufacturing process which results in the development of bacterial 
contaminants posing a threat for the consumers. Skin and mucous membranes are normally protected from microbial attack, however protective integuments may be damaged and slight trauma may result. These situations may be of particular concern when contaminated cosmetics are used in the mucocutaneous membranes or on damaged skin and when used by people having compromised immune responses [5]. Many studies carried out across the world showed high rate of contamination of cosmetics by Staphylococcus spp., Pseudomonas spp., Clostridium spp., Candida spp. and Enterobacteriaceae. Both these organisms are opportunistic pathogens. If these bacterial contaminants from skin moisturizing lotions cause any skin infection during its use, then it should be treated. The excessive use of antibiotics can lead to increased resistance in bacterial pathogens. To overcome the problem of antibiotic resistance medicinal plant extracts have been extensively studied as an alternative as they have fewer adverse effects than synthetic agents. Hence, the present investigation was carried out to evaluate and screen the bacterial contaminants from skin moisturizing lotions and to study its antibiotic resistance pattern as well as antibacterial activity of herbal extracts.

\section{MATERIALS AND METHODS:}

\section{Sample Collection:}

A total of 22 skin moisturizing lotions representing different brands were collected from beauty parlours of Nagpur region.

\section{Analysis of Bacterial Contaminants:}

Isolation of bacterial contaminants from skin moisturizing lotions on Mannitol Salt Agar and Pseudomonas Isolation Agar was carried out. For this, 1 gram of each sample of skin moisturizing lotion was added into $9 \mathrm{ml}$ nutrient broth and incubated overnight at $37^{\circ} \mathrm{C}$. A loopful inoculum was inoculated on the media plates and incubated at $37^{\circ} \mathrm{C}$ for 24 hours. After incubation, isolates were identified on the basis of morphological, cultural and biochemical characteristics [6] [7] [8].

\section{Antibiotic Susceptibility of Bacterial Contaminants:}

Antimicrobial activity was performed using disk diffusion method according to NCCLS standard [9]. Different types of antibiotics for each type of bacterial contaminant were used in the present study (Table 1).
A sterile swab was dipped into bacterial suspension, pressed on side of the test tube to allow excess dripoff, and was then evenly streaked on the entire surface of the Mueller-Hinton agar plate. The antibiotic discs were placed on the plate with the help of sterile forcep. The plates were incubated at $37^{\circ} \mathrm{C}$ for $24 \mathrm{hrs}$. After incubation, the zone of inhibition of was measured [8].

\section{Antibacterial Activity of Herbal Extracts:}

Neem leaves (Azadirachta indica) and Daru Haldi stem (Berberis aristata) were collected and used for extract preparation. Neem extract was prepared by mixing $10 \mathrm{gm}$ of dried Neem leaves powder into water ethanol mixture as a solvent in 7:3 ratio and refluxed for 3 hours.

Daru Haldi extract was prepared by mixing 20 gm of Daru Haldi stem powder into ethanol water mixture as a solvent in 7:3 ratio and refluxed for 3 hours. After cooling, both the extracts were filterted and used separately for the study [11]. Wells $(6 \mathrm{~mm})$ were made on Mueller Hinton agar plate lawned with the bacterial culture. A $50 \mathrm{ul}$ of the extract was added in the well and the plates were incubated at $37^{\circ} \mathrm{C}$ for 24 hrs. After incubation, the zone of inhibition was measured.

\section{RESULTS AND DISCUSSION:}

The present investigation was carried out to analyze the presence of potential bacterial contaminants in different skin moisturizing lotions. A total of 22 different types of skin moisturizing lotions representing different brands were analyzed in the present study. Out of which, Staphylococcus aureus were isolated from 7 moisturizing lotions while Pseudomonas aeruginosa were isolated from 8 lotions. These results were correlated with the previous findings [10]. Both these organisms are opportunistic pathogens. In the earlier studies it was came to the conclusion that skin lotions shows high incidence of contamination rate by Staphylococcus spp. [3] [4]. The most predominantly isolated gram positive bacterium was found to be $S$. aureus. It is known to cause skin and soft tissue infections and the application of creams with the presence of this organism may result in boils and impetigo. Among the gram negative organisms, $P$. aeruginosa was the predominantly isolated organism, and this bacterium is well known to cause infection of burns, wounds and eyes. 
The antibiotic susceptibility test of the isolated bacterial contaminants was carried out against different types of antibiotics for each type of bacterial contaminant isolated. The results of the test revealed that all the isolates of S. aureus were sensitive against tested antibiotics (Graph 1) while 2 isolates of $P$. aeruginosa were resistant to Gentamycin and Carbenicillin and 1 to Levofloxacin (Graph 2). The present findings were correlated with that of the previous work in which it was reported that erythromycin against $S$. aureus and Gentamycin against $P$. aeruginosa showed highest activity [8]. When the bacterial contaminants were tested against Neem and Daru Haldi extracts, it was found that the extracts were effective against it. The results were correlated with the previous findings [11]. It has reported that Neem leaves have known to possess diverse pharmacological properties like anti inflammatory, anti pyretic and anti microbial [12]. In Daru Haldi, the major alkaloid berberine is responsible for antimicrobial activity. It also acts as anti inflammatory, wound healing and anti oxidant [13] [14]. Hence according to present findings, Neem and Daru Haldi can be used as potential natural remedy against skin infecting pathogens isolated from skin moisturizing lotions.

The common ingredients used in preparation of cosmetics include sugar, starch, protein, amino acids, organic acids, alcohols and lipids which favours microbial growth. Water is a fundamental requirement for any microorganisms to multiply and contaminate the cosmetics products; thus untreated or non sterile water can enhance microbial growth leading to contamination of cosmetics products [4]. The sources of microbial contaminants in cosmetics at the point of sale are raw materials used in production, personnel, and the environment in which products are manufactured [15].

\section{CONCLUSION:}

Cosmetics are extremely vulnerable to microbial contamination. This attributes to the presence of water and raw materials which facilitates the growth of microbes. The findings of this study conclude that facial skin lotions may contain harmful bacterial contaminants such as Staphylococcus aureus and Pseudomonas aeruginosa posing a serious threat for the consumers. Good Manufacturing Practice should be followed; raw materials and water should be tested microbiologically. It is necessary to carry out routine microbiological control tests for cosmetics after manufacturing in order to ensure the quality and safety for customer. Hence it is the need of an hour to evaluate and control the microbiological quality of skin products during its production and formulations.

\section{REFERENCES}

[1] P. Hashim, N. Shahab, T. Masilamani, R. Baharom, R. and Ibrahim. A Cosmetic Analysis in Compliance with the Legislative Requirements, Halal and Quality Control. Malaysian J. Chem., vol. 11(1), pp. 81-87, 2009.

[2] W. Siegert, Schulke and M. Gombh. Microbiological Quality Management for the Production of Cosmetics and Toiletries. Cosmet. Sci. Tech., 2005.

[3] I.N. Okeke and A. Lamikanra. Bacteriological quality of skin moisturizing creams and lotions distributed in a tropical developing country. J. Appl. Microbiol., vol. 91, pp. 922-928, 2001.

[4] P.G. Hugbo, A.O. Onyekweli and Igwe, I. Microbial contamination and preservative capacity of some brands of cosmetic creams. Tropical Journal of Pharmaceutical Research, vol. 2, pp. 229-234, 2003.

[5] M.T. Parker. The clinical significance of the presence of microorganisms in pharmaceutical and cosmetic preparations. Journal of the Society of Cosmetic Chemists, vol. 23, pp. 415-416, 1972.

[6] J.G. Collee, R.S. Miles and B. Waatt. Tests for the identification of Mackie and Mc Cartney Practical Medical Microbiology, 14th ed, In: Collee JG, Fraser AG, Marmion BP, Simmons A, editors. London: Churchill Livingstone; pp. 131149, 1996.

[7] M. Cheesbrough. District laboratory practice in tropical countries. Part 2, pp. 63-130, 267-332, 2005.

[8] M. Aminu and O. Christopher. Antibiogram of bacterial isolates and fungi associated with some creams and lotions sold in Zaria, Nigeria. African Journal of Microbiology Research, vol. 10(7), pp. 231-237, 2016.

[9] A.W. Bauer, W.M.M. Kirby, J.C. Sherirs and M. Turck. Antibiotic susceptibility testing by standard single disk method. American Journal of Clinical Pathology, vol. 45, pp. 433-496, 1966.

[10] S. Rafiq, S. Iqbal and J.S. Shaik. Bacteriological Profile and Preservative Capacity of Commercial 
International Journal of Trend in Scientific Research and Development (IJTSRD) ISSN: 2456-6470

Creams and Lotions. UK Journal of Pharmaceutical and Biosciences, 2015.

[11] F.S. Daud, G. Pande, M.Joshi, R. Pathak and S. Wankhede. A study of antibacterial effect of some selected essential oils and medicinal herbs against acne causing bacteria. International Journal of Pharmaceutical Science Invention, vol. 2, pp. 27-34, 2013.

[12] R. Arora, S. Singh and R.K Sharma, In: Botanical Medicine in Clinical Practice, Edited by Ronald Watson and Victor Preedy, CABI, 2008.
[13] S. Das. Phyto-Pharmacology of Berberis Aristata DC: A Review. Journal of Drug Delivery and Therapeutics, vol. 1, pp. 46-50, 2011.

[14] K. Sharma. Berberis Aristata: A Review, IJRAP, vol. 2, pp. 383-388, 2011.

[15] S.O. Olson. The application of microbiology to cosmetic testing. Journal of the Society of Cosmetic Chemists, vol. 18, pp. 191-198, 1967.

Table 1: Antibiotics Used in the study

\begin{tabular}{|c|c|}
\hline Antibiotics & Concentration \\
\hline Amoxyclav & $30 \mathrm{mcg}$ \\
\hline Azithromycin & $15 \mathrm{mcg}$ \\
\hline Carbenicillin & $100 \mathrm{mcg}$ \\
\hline Clindamycin & $2 \mathrm{mcg}$ \\
\hline Erythromycin & $15 \mathrm{mcg}$ \\
\hline Gentamycin & $10 \mathrm{mcg}$ \\
\hline Levofloxacin & $5 \mathrm{mcg}$ \\
\hline Vancomycin & $30 \mathrm{mcg}$ \\
\hline
\end{tabular}

Table 2: Antimicrobial Activity of Antibiotics and Herbal Extracts against S. aureus

\begin{tabular}{|c|c|c|c|c|c|c|c|}
\hline S. aureus & 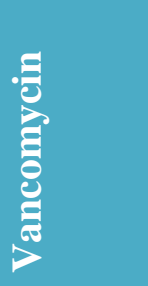 & 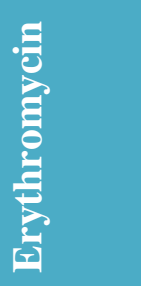 & 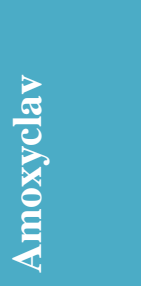 & 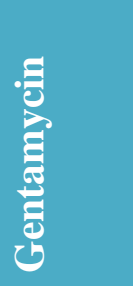 & 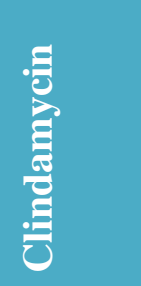 & $\begin{array}{l}\Xi \\
\overline{8} \\
Z \\
Z\end{array}$ & 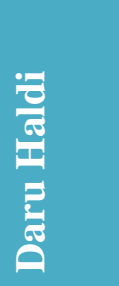 \\
\hline S. aureus 1 & $18 \mathrm{~mm}$ & $15 \mathrm{~mm}$ & $13 \mathrm{~mm}$ & $23 \mathrm{~mm}$ & $24 \mathrm{~mm}$ & $15 \mathrm{~mm}$ & $18 \mathrm{~mm}$ \\
\hline S. aureus 2 & $15 \mathrm{~mm}$ & $16 \mathrm{~mm}$ & $17 \mathrm{~mm}$ & $17 \mathrm{~mm}$ & $22 \mathrm{~mm}$ & $16 \mathrm{~mm}$ & $18 \mathrm{~mm}$ \\
\hline S. aureus 3 & $18 \mathrm{~mm}$ & $19 \mathrm{~mm}$ & $13 \mathrm{~mm}$ & $19 \mathrm{~mm}$ & $21 \mathrm{~mm}$ & $16 \mathrm{~mm}$ & $17 \mathrm{~mm}$ \\
\hline S. aureus 4 & $20 \mathrm{~mm}$ & $18 \mathrm{~mm}$ & $13 \mathrm{~mm}$ & $22 \mathrm{~mm}$ & $13 \mathrm{~mm}$ & $17 \mathrm{~mm}$ & $19 \mathrm{~mm}$ \\
\hline S. aureus 5 & $21 \mathrm{~mm}$ & $16 \mathrm{~mm}$ & $20 \mathrm{~mm}$ & $22 \mathrm{~mm}$ & $16 \mathrm{~mm}$ & $16 \mathrm{~mm}$ & $18 \mathrm{~mm}$ \\
\hline S. aureus 6 & $13 \mathrm{~mm}$ & $15 \mathrm{~mm}$ & $13 \mathrm{~mm}$ & $12 \mathrm{~mm}$ & $23 \mathrm{~mm}$ & $15 \mathrm{~mm}$ & $18 \mathrm{~mm}$ \\
\hline S. aureus 7 & $16 \mathrm{~mm}$ & $14 \mathrm{~mm}$ & $23 \mathrm{~mm}$ & $13 \mathrm{~mm}$ & $26 \mathrm{~mm}$ & $15 \mathrm{~mm}$ & $17 \mathrm{~mm}$ \\
\hline
\end{tabular}


Table 3: Antimicrobial Activity of Antibiotics and Herbal Extracts against $P$. aeruginosa

\begin{tabular}{|c|c|c|c|c|c|c|c|}
\hline P. aeruginosa & 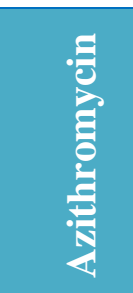 & 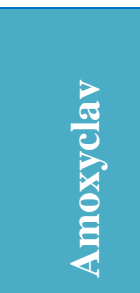 & 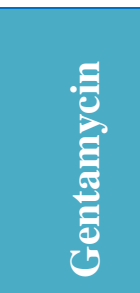 & 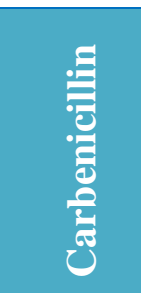 & 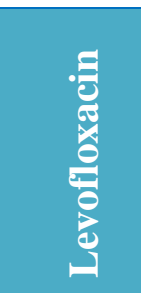 & $\begin{array}{l}\text { E } \\
\text { ¿ } \\
\text { Z }\end{array}$ & 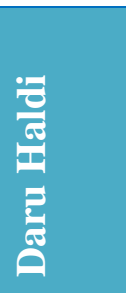 \\
\hline P. aeruginosa 1 & $14 \mathrm{~mm}$ & $29 \mathrm{~mm}$ & $18 \mathrm{~mm}$ & $\mathrm{R}$ & $19 \mathrm{~mm}$ & $16 \mathrm{~mm}$ & $18 \mathrm{~mm}$ \\
\hline P. aeruginosa 2 & $13 \mathrm{~mm}$ & $12 \mathrm{~mm}$ & $\mathrm{R}$ & $\mathrm{R}$ & $28 \mathrm{~mm}$ & $15 \mathrm{~mm}$ & $18 \mathrm{~mm}$ \\
\hline P. aeruginosa 3 & $13 \mathrm{~mm}$ & $13 \mathrm{~mm}$ & $25 \mathrm{~mm}$ & $13 \mathrm{~mm}$ & $27 \mathrm{~mm}$ & $16 \mathrm{~mm}$ & $19 \mathrm{~mm}$ \\
\hline P. aeruginosa 4 & $13 \mathrm{~mm}$ & $21 \mathrm{~mm}$ & $16 \mathrm{~mm}$ & $26 \mathrm{~mm}$ & $23 \mathrm{~mm}$ & $16 \mathrm{~mm}$ & $18 \mathrm{~mm}$ \\
\hline P. aeruginosa 5 & $16 \mathrm{~mm}$ & $13 \mathrm{~mm}$ & $\mathrm{R}$ & $21 \mathrm{~mm}$ & $\mathrm{R}$ & $17 \mathrm{~mm}$ & $18 \mathrm{~mm}$ \\
\hline P. aeruginosa 6 & $13 \mathrm{~mm}$ & $16 \mathrm{~mm}$ & $20 \mathrm{~mm}$ & $13 \mathrm{~mm}$ & $15 \mathrm{~mm}$ & $15 \mathrm{~mm}$ & $17 \mathrm{~mm}$ \\
\hline P. aeruginosa 7 & $13 \mathrm{~mm}$ & $11 \mathrm{~mm}$ & $26 \mathrm{~mm}$ & $10 \mathrm{~mm}$ & $28 \mathrm{~mm}$ & $15 \mathrm{~mm}$ & $18 \mathrm{~mm}$ \\
\hline P. aeruginosa 8 & $21 \mathrm{~mm}$ & $10 \mathrm{~mm}$ & $21 \mathrm{~mm}$ & $10 \mathrm{~mm}$ & $26 \mathrm{~mm}$ & $16 \mathrm{~mm}$ & $17 \mathrm{~mm}$ \\
\hline
\end{tabular}

Where, R- Resistant

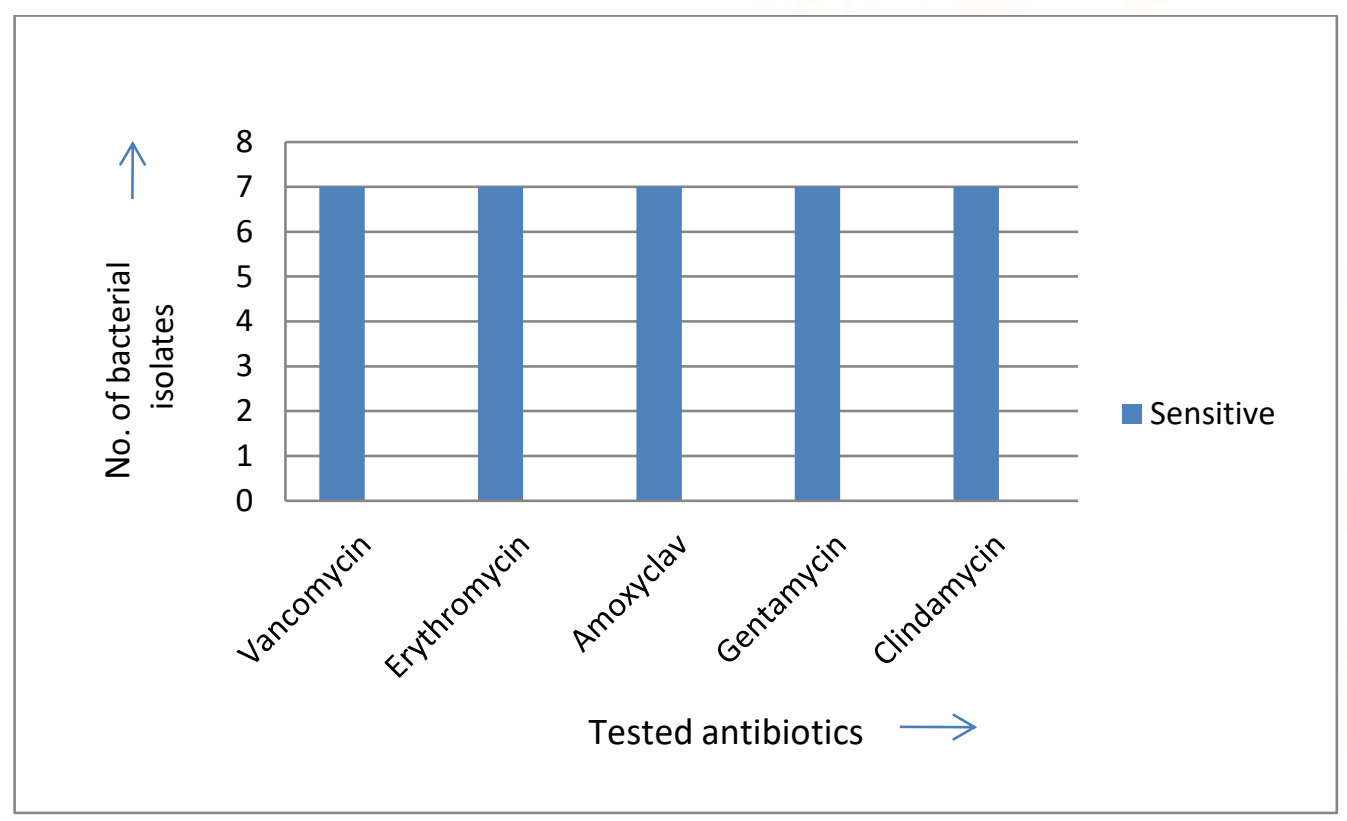

Graph 1: Antibiotic Susceptibility Profile of S. aureus 


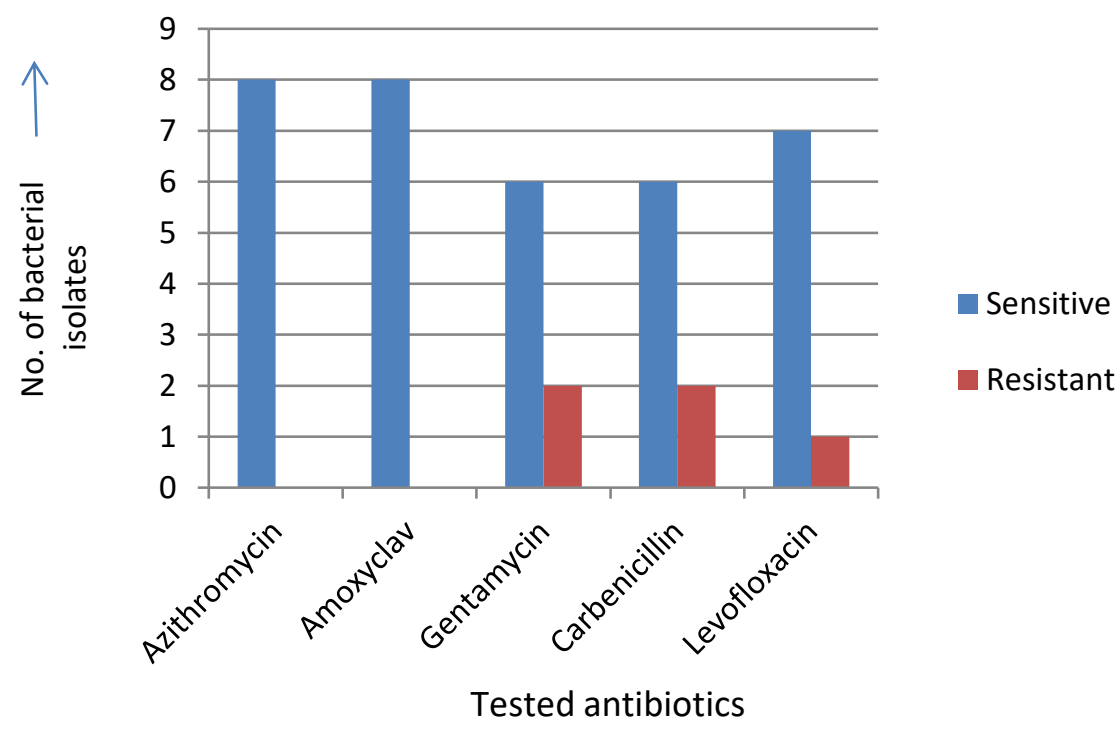

Graph 2: Antibiotic Susceptibility Profile of $\boldsymbol{P}$. aeruginosa 